Hydrol. Earth Syst. Sci., 17, 4015-4030, 2013

www.hydrol-earth-syst-sci.net/17/4015/2013/

doi:10.5194/hess-17-4015-2013

(c) Author(s) 2013. CC Attribution 3.0 License.

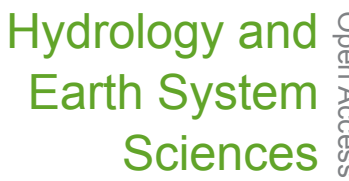

\title{
Evaluating scale and roughness effects in urban flood modelling using terrestrial LIDAR data
}

\author{
H. Ozdemir ${ }^{1}$, C. C. Sampson ${ }^{2}$, G. A. M. de Almeida ${ }^{3}$, and P. D. Bates ${ }^{2}$ \\ ${ }^{1}$ Physical Geography Division, Geography Department, Istanbul University, 34459 Istanbul, Turkey \\ ${ }^{2}$ School of Geographical Sciences, University of Bristol, Bristol, BS8 1SS, UK \\ ${ }^{3}$ Faculty of Engineering and the Environment, University of Southampton, Southampton, SO171BJ, UK \\ Correspondence to: H. Ozdemir (ozdemirh@ istanbul.edu.tr)
}

Received: 9 April 2013 - Published in Hydrol. Earth Syst. Sci. Discuss.: 14 May 2013

Revised: 1 August 2013 - Accepted: 5 September 2013 - Published: 17 October 2013

\begin{abstract}
This paper evaluates the results of benchmark testing a new inertial formulation of the St. Venant equations, implemented within the LISFLOOD-FP hydraulic model, using different high resolution terrestrial LiDAR data $(10 \mathrm{~cm}$, $50 \mathrm{~cm}$ and $1 \mathrm{~m}$ ) and roughness conditions (distributed and composite) in an urban area. To examine these effects, the model is applied to a hypothetical flooding scenario in Alcester, UK, which experienced surface water flooding during summer 2007. The sensitivities of simulated water depth, extent, arrival time and velocity to grid resolutions and different roughness conditions are analysed. The results indicate that increasing the terrain resolution from $1 \mathrm{~m}$ to $10 \mathrm{~cm}$ significantly affects modelled water depth, extent, arrival time and velocity. This is because hydraulically relevant small scale topography that is accurately captured by the terrestrial LIDAR system, such as road cambers and street kerbs, is better represented on the higher resolution DEM. It is shown that altering surface friction values within a wide range has only a limited effect and is not sufficient to recover the results of the $10 \mathrm{~cm}$ simulation at $1 \mathrm{~m}$ resolution. Alternating between a uniform composite surface friction value $(n=0.013)$ or a variable distributed value based on land use has a greater effect on flow velocities and arrival times than on water depths and inundation extent. We conclude that the use of extra detail inherent in terrestrial laser scanning data compared to airborne sensors will be advantageous for urban flood modelling related to surface water, risk analysis and planning for Sustainable Urban Drainage Systems (SUDS) to attenuate flow.
\end{abstract}

\section{Introduction}

Urban flood events are increasing in frequency and severity as a consequence of: (1) reduced infiltration capacities due to continued watershed development (Hsu et al., 2000); (2) increased construction in flood prone areas due to population growth (Brown et al., 2007; Mason et al., 2007); (3) the possible amplification of rainfall intensity due to climate change; (4) sea level rise which threatens coastal development; and (5) poorly engineered flood control infrastructure (Gallegos et al., 2009). These factors will contribute to increased urban flood risk in the future, and as a result improved modelling of urban flooding has been identified as a research priority (Wheater, 2002; Gallegos et al., 2009; Tsubaki and Fujita, 2010; Fewtrell et al., 2011; Sampson et al., 2012). Surface water flood, which is one of the main sources of urban flooding after fluvial and coastal, occurs when natural and man-made drainage systems have insufficient capacity to deal with the volume of rainfall. The Environment Agency of England and Wales (EA) estimated that of the 55000 properties affected by the UK June 2007 floods, around two thirds were flooded as a result of excess surface water runoff (DEFRA, 2008). Moreover, it is estimated that 80000 properties are at very significant risk from surface water flooding (10\% annual probability or greater), causing on average GBP 270 million of damage each year. As a result, the 2007 event showed that the necessity of researches on surface water flooding risk besides fluvial and coastal risk (Pitt, 2008).

Current active research areas in surface water flooding include the representation of micro-scale topographic and 
blockage effects (e.g. kerbs, road surface camber, wall, buildings) and the development of numerical schemes capable of representing high-velocity shallow flow at fine spatial resolutions over low friction surfaces in urban environments. Over the last decade, studies investigating the role of topography in urban flood models have typically employed airborne LiDAR terrain models of $\sim 50 \mathrm{~cm}-3 \mathrm{~m}$ horizontal resolution (Mason et al., 2007; Brown et al., 2007; Fewtrell et al., 2008; Hunter et al., 2008; Gallegos et al., 2009; Neal et al., 2009; Tsubaki and Fujita, 2010). However, small scale features which have significant impact on the flood propagation and especially surface water flooding in urban environments (Hunter et al., 2008; Fewtrell et al., 2011; Sampson et al., 2012) cannot be distinguished in airborne LiDAR data. Because of that, terrestrial laser scanners have started to be employed to capture even more detailed (i.e. $\sim 1-3 \mathrm{~cm}$ horizontal resolution) 3-D point cloud data for applications in engineering, transportation and urban planning (Barnea and Filin, 2008; Lichti et al., 2008). Fewtrell et al. (2011) analysed the utility of high resolution terrestrial LiDAR data in simulating surface water flooding and found that the road cambers and kerbs represented in the high resolution grid terrestrial LiDAR DEM had a significant impact on simulated flows. Sampson et al. (2012) also highlighted that inclusion of small scale topographic features resolved by the terrestrial laser scanner improves the representation of hydraulic connectivity across the domain. Variable mesh generation provides an alternative to high resolution grids for representing detailed features in urban environments (Yu and Lane, 2006a; Schubert et al., 2008), and a detailed comparison between variable mesh models and grid-based models for inundation modelling is given by Neal et al. (2011).

The benchmarking of two-dimensional (2-D) hydraulic models and the influence of floodplain friction on rural floodplains are now relatively well understood as a result of various model applications over the last two decades (Gee et al., 1990; Bates et al., 1998; Horritt, 2000; Bates and De Roo, 2000; Horritt and Bates, 2002; Nicholas and Mitchell, 2003; Hunter et al., 2005; Werner et al., 2005; Néelz et al., 2006). A number of studies have documented the application of 2-D hydraulic models, such as numerical solutions of the full 2D shallow-water equations, 2D diffusion wave models, and analytical approximations to the 2-D diffusion wave using uniform flow formulae, to complex urban problems (Aronica and Lanza, 2005; Mignot et al., 2006; Guinot and Soares-Frazao, 2006; Hsu et al., 2000; Yu and Lane, 2006a,b; Fewtrell et al., 2008; Néelz and Pender, 2010). Practical application of full-dynamic shallow water models to large areas to resolve flows at high resolution is often limited due to the extremely high computational cost. On the other hand, most simplified formulations lack the generality needed to capture the wide range of flow conditions usually taking place in urban areas. To address this issue, Bates et al. (2010) derived a simplified or "inertial" shallow water model which represents a good balance between computational performance and the representation of the most relevant physical processes needed to model urban flood propagation. Solutions using the new equation set are shown to be grid-independent and to have an intuitively correct sensitivity to friction. However, small instabilities and increased errors on predicted depth were noted by Bates et al. (2010) under low friction conditions ( $\mathrm{n}<0.03$ ) that may be typical of skin frictions in urban areas. Fewtrell et al. (2011) tested diffusive and inertial equations using terrestrial LiDAR data and a high single composite friction value $(n=0.035)$ in urban areas. They noted that the computational cost is considerably reduced in the inertial formulation compared to a diffusive wave approximation in high resolution model simulations. In terms of friction parameters, whilst many flood inundation models have commonly used a uniform roughness coefficient for the floodplain (Bates and De Roo, 2000; Horritt and Bates, 2002), some researchers have used spatially-distributed friction in both rural and urban areas (Werner et al., 2005; Wilson and Atkinson, 2007; Schubert at al., 2008; Gallegos et al., 2009). For the urban case, Gallegos et al. (2009) noted that a spatially uniform resistance parameter lead to poor stream flow accuracy compared to a spatially distributed parameter. This was confirmed by Schubert et al. (2008) who found that flood extent, flood depth and arrival times were sensitive to roughness parameter spatial distributions for a test case in Glasgow, UK. An unresolved question however is how topographic and friction effects interact and are influenced by the model grid scale at terrestrial LiDAR resolutions. At such scales terrain data at $1-3 \mathrm{~cm}$ point spacing begin to resolve explicitly some of the structural elements responsible for generating frictional losses at coarser grid scales. Looking at model sensitivity to friction on a variety of fine spatial resolution grids parameterized using terrestrial LiDAR data can shed light on: (1) whether micro terrain features generate frictional losses at coarser grid scales; (2) whether such frictional losses can be easily parameterized in coarser scale models; and (3) which terrain features cannot be treated in this way and need to be explicitly represented in the model grid.

In densely urbanized areas where relatively smooth surfaces are found, the simulation of surface water floods using a very fine resolution DEM (below $1 \mathrm{~m}$ ) and very low friction values (below $n=0.020$ ) may also cause numerical instabilities to arise in shallow water models as these strictly only apply to slopes with gradients $<10 \%$. An inevitable consequence of capturing finer resolution DEM data and surveying topography from sideways looking terrestrial laser scanners rather than nadir pointing airborne LiDAR systems is that small scale features such as kerbs and walls are much better resolved. A $10 \mathrm{~cm}$ kerb height drop when sampled at typical airborne LiDAR resolutions $(1-2 \mathrm{~m})$ does not create gradients above $10 \%$, and such features are often not even correctly seen by the sensor (Sampson et al., 2012). However, the same feature when sampled using a sideways looking terrestrial laser system with $\sim 1-3 \mathrm{~cm}$ point spacing will be easily resolved, and when the raw point cloud terrain data 
are re-sampled on up to $1 \mathrm{~m}$ grids slopes can be generated which breach the assumptions of the shallow water equations. On a $10 \mathrm{~cm}$ grid a $10 \mathrm{~cm}$ vertical drop results in a bed gradient of $50 \%$ which can be very difficult for many shallow water based models to deal with (Hunter et al., 2008; Gallegos et al., 2009; Neal et al., 2011). In terms of numerical stability and accuracy de Almeida et al. (2012) proposed and tested a new numerical scheme for the simplified shallow water model of Bates et al. (2010) able to improve stability significantly. Yet this has still to be evaluated for use in urban areas surveyed with terrestrial laser DEM data and simulated with sub-metre scale model grids.

The primary aim of this paper is therefore to apply and test the new numerical scheme proposed by de Almeida et al. (2012) using different surface friction configurations (spatially distributed or single composite value) on high resolution DEMs derived from terrestrial LiDAR. We start by describing the data and methods, including a description of the test site, data sources and the improved formulation of LISFLOOD-FP, before applying this model to varying resolution terrestrial LiDAR DEMs with distributed and composite surface friction values. The results are then presented and discussed in terms of water depths, extents, arrival times and velocities before the conclusion are drawn and implications stated.

\section{Data and method}

\subsection{Site and event description}

Alcester in Warwickshire experienced extensive flooding the Rivers Alne and Arrow during the floods of July 2007 in the United Kingdom, with the closest gauges on the River Arrow recording flows with a return period of 1 in $200 \mathrm{yr}$. Moreover, the local drainage system was overwhelmed by excess rainfall $(60-80 \mathrm{~mm}$ rainfall over a $12 \mathrm{~h}$ period). The combination of these two events led to flooding of 150 properties with both fluvial and surface water, although the Environment Agency of England and Wales (EA) estimate that a further 200 properties were successfully protected by the current flood defences. Furthermore, the EA estimates that $\sim 260$ properties in Alcester lie within the 1-in-100 yr floodplain ( $\geq 1 \%$ chance of fluvial flooding each year) and substantial areas of the town are at risk from surface water. In response to this flooding, the height of the flood wall in Alcester has been increased to ensure that it is above the July 2007 river levels and two new pumping stations have been installed to expel water from the town when the drainage system capacity is exceeded (EA, 2011). The section of Alcester chosen for this study lies in an area susceptible to flooding both from the River Arrow and surface water overwhelming the drainage system. The motivation for the terrestrial LiDAR collection, therefore, was to understand the detailed hydraulics of water flow in this region. The test site has an area of $0.1 \mathrm{~km}^{2}$ and consists of 4 streets with a number of cul-de-sacs feeding off them (Fig. 1).

Although the area selected is prone to flooding from fluvial and surface water sources, there are no reliable estimates of flood volumes for an observed flood event in the area. As the aim of this study is to determine scale and roughness effects for terrestrial LiDAR data in urban modelling, rather than to develop a detailed understanding of flood risk at Alcester, the model boundary conditions need to be sufficiently realistic to approximate a typical surface water flood but do not need to precisely reflect the actual conditions at the site. Therefore, the inflow boundary conditions for this test case were derived using the depth-duration-frequency method for estimating rainfall from volume 2 of the UK Flood Estimation Handbook, with local parameters derived from the accompanying Flood Estimation Handbook CD-ROM (FEH, Institute of Hydrology, 1999). For this study, we assume that the 200yr 30-min rainfall $(47 \mathrm{~mm})$ is collected over a drainage area of $100 \times 100 \mathrm{~m}$ upstream of the inflow point (see Fig. 1) to represent the flow coming from a blocked culvert opening draining a small catchment. The accumulated volumes have been transformed into the simple $30 \mathrm{~min}$ inflow hydrograph shown in Fig. 2, where we assume inflow to increase linearly from $0 \mathrm{~m}^{3} \mathrm{~s}^{-1}$ to peak rate over the initial $7.5 \mathrm{~min}$ of the event, remaining at the peak rate for the subsequent $15 \mathrm{~min}$ before falling linearly back to $0 \mathrm{~m}^{3} \mathrm{~s}^{-1}$ over the final $7.5 \mathrm{~min}$. The final assumption in this study is that the drainage system is operating at capacity such that water on the surface does not interact with the drains at the road side. Whilst observed data of the flooding would be of value, its absence does not limit the present study whose aim is to understand scaling effects for terrestrial laser data using a sensitivity analysis.

\subsection{Terrestrial LiDAR data collection and processing}

The high resolution elevation data of Alcester used in this study were collected by the Environment Agency Geomatics Group using the LYNX Mobile Mapper ${ }^{\mathrm{TM}}$ system distributed by Optech Incorporated. The LYNX Mobile Mapper ${ }^{\mathrm{TM}}$ consists of two $100 \mathrm{kHz}$ LiDAR instruments, each with $360^{\circ}$ field of view, mounted on a rigid platform on the back of a Land Rover. Two GPS receivers are mounted on the roof of the car, one at the front and one on the rigid platform at the back. In addition, an inertial measurement unit (IMU) is centred on the rigid platform and a sensor is mounted on the wheel to record rotations and steering direction in order to provide dead reckoning estimates of position if the GPS signal is weak. The GPS system uses the principle of real time kinematic (RTK) navigation whereby the roving LYNX unit calculates a relative position based on a known base station with accuracies of $\pm 5 \mathrm{~cm}$. The system is capable of recording 4 simultaneous measurements per laser pulse which results in $1 \mathrm{~GB} \mathrm{~s}^{-1}$ of point cloud data generation (http://www.optech.ca/lynx.htm). 


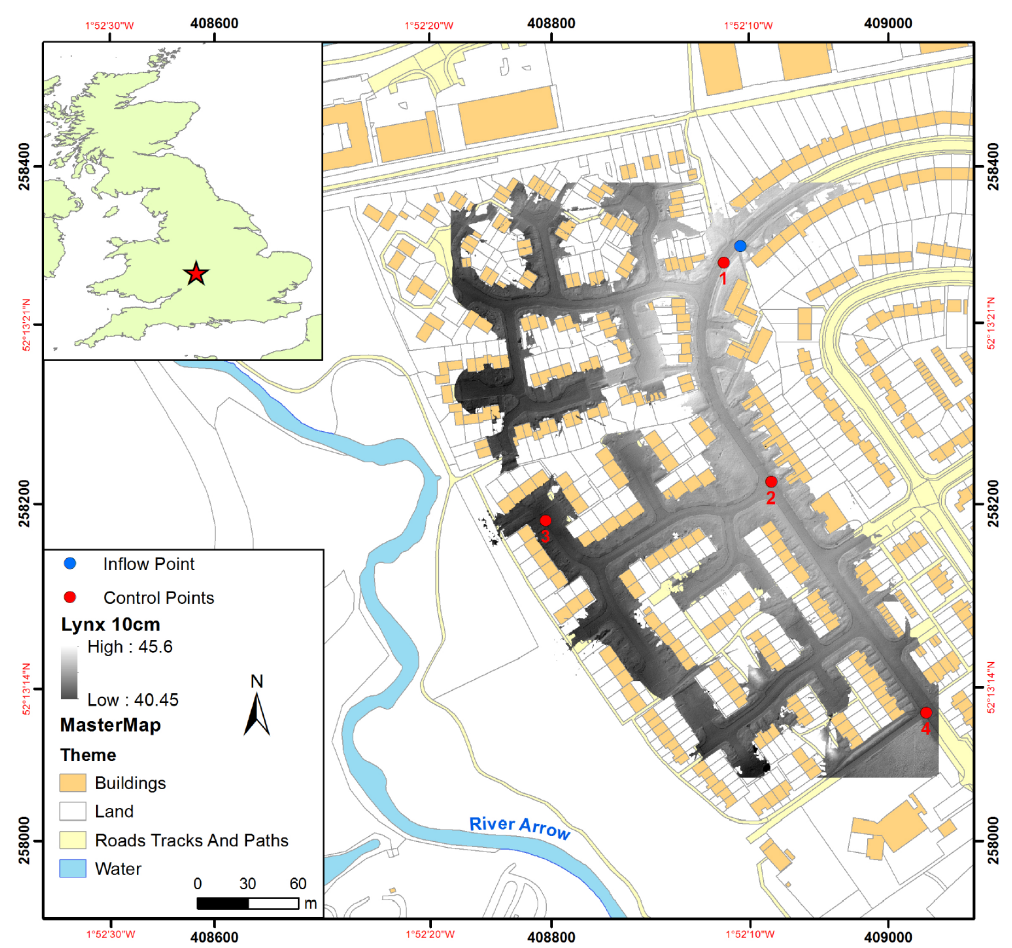

Fig. 1. MasterMap ${ }^{\circledR}$ data of study area in Alcester with over plotted $10 \mathrm{~cm}$ LYNX data of the model domain. The locations of the assumed sewer surcharge inflow point and the control points are highlighted.

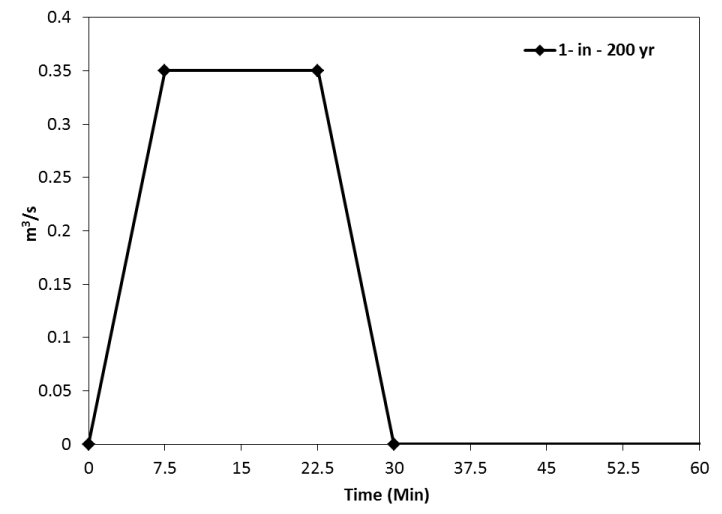

Fig. 2. Inflow boundary conditions.

The terrestrial LiDAR point cloud is processed into a DEM using proprietary processing algorithms developed by EA. The main purpose of LiDAR segmentation is to separate ground hits from surface objects such as vegetation and buildings returns. However, in terrestrial LiDAR surveys there is an additional need to separate long range points caused by reflection off car surfaces and the interior of buildings from the ground pulse hits. This is achieved using classification algorithms in an iterative procedure in order to progressively remove surface objects from the underlying surface topography (see for detail Sampson et al., 2012). The resulting surface was aggregated to a raster DEM at
$10 \mathrm{~cm}$ resolution $(3616663$ cells) then resampled to $50 \mathrm{~cm}$ (144659 cells) and $1 \mathrm{~m}$ (36242 cells) using a simple nearest neighbour resample method (Fewtrell et al., 2008) to investigate the scale dependency of flooding at this site.

\subsection{Model description}

LISFLOOD-FP is a software package designed to model the propagation of water over complex topography typically represented by raster data. The package is a mature system that has undergone extensive development and testing since conception (e.g. Bates and De Roo, 2000; Hunter et al., 2005; Bates et al., 2010). The current version (Version 5.7.6) consists of a collection of numerical schemes implemented to solve a variety of mathematical approximations of the 2-D shallow water equations of different complexity (ranging from an extremely simple diffusive wave model to a shock capturing Godunov-type scheme based on the Roe Riemann solver which solves the full shallow water equations; Roe, 1981; Toro, 1999, 2001; LeVeque, 2002; Villanueva and Wright, 2005). Among these different formulations, that proposed by Bates et al. (2010) has attracted increasing attention for modelling flood propagation over large urban areas. It solves a simplified inertial version of the Saint-Venant equations (e.g. Ponce, 1990; Xia, 1994; Aronica et al., 1998; Bates et al., 2010; de Almeida et al., 2012) which neglects the convective acceleration term in the 
momentum conservation equation, yielding a system of three partial differential equations:

$$
\begin{aligned}
& \frac{\partial h}{\partial t}+\frac{\partial q_{x}}{\partial x}+\frac{\partial q_{y}}{\partial y}=0 \\
& \frac{\partial q_{x}}{\partial t}+g h \frac{\partial(h+z)}{\partial x}+\frac{g n^{2}\left|q_{x}\right| q_{x}}{h^{7 / s}}=0 \\
& \frac{\partial q_{y}}{\partial t}+g h \frac{\partial(h+z)}{\partial y}+\frac{g n^{2}\left|q_{y}\right| q_{y}}{h^{7 / s}}=0
\end{aligned}
$$

where $q\left[\mathrm{~L}^{2} \mathrm{~T}^{-1}\right]$ is the discharge per unit width, $h[\mathrm{~L}]$ is the water depth, $z[\mathrm{~L}]$ is the bed elevation, $g\left[\mathrm{~L} \mathrm{~T}^{-2}\right]$ is the acceleration due to gravity, $n\left[\mathrm{~T} \mathrm{~L}^{-1 / 3}\right]$ is the Manning friction coefficient, $x[\mathrm{~L}]$ and $y[\mathrm{~L}]$ are the horizontal coordinates and $t[\mathrm{~T}]$ is the time. These equations were originally solved using a simple finite difference scheme applied to a staggered structured grid of square cells, which leads to a system of three explicit equations in two horizontal dimensions (Bates et al., 2010). Previous applications of this formulation have reported problems of numerical instability in domains with relatively low friction (typically $n<0.03$ ), which imposes particular limitations to simulations of urban areas, where smooth surfaces are typically abundant.

de Almeida et al. (2012) proposed a modification of the Bates et al. (2010) numerical scheme that significantly stabilises the solution in these low friction scenarios. The resulting model provides a robust solution to flood propagation problems over complex topographies at very low computational cost. In this scheme, water flux at the interfaces of two adjacent cells (i.e. $q_{x}$ and $q_{y}$ ) is calculated using the following discretization of the simplified momentum conservation equation (Eqs. 2 and 3):

$q_{i-1 / 2}^{n+1}=\frac{\theta q_{i-1 / 2}^{n}+\frac{(1-\theta)}{2}\left(q_{i-3 / 2}^{n}+q_{i+1 / 2}^{n}\right)-g h_{f} \frac{\Delta t}{\Delta x}\left(y_{i}^{n}-y_{i-1}^{n}\right)}{1+\frac{g \Delta t}{2} n^{2} q_{i-1 / 2}^{n}} h_{f}^{7 / 3}$

where $h_{f}$ is defined as the difference between max $\left(y_{i}, y_{i-1}\right)$ and max $\left(z_{i}, z_{i-1}\right)$, and $(\theta)$ is a spatial weighting factor that is used to control the amount of numerical diffusion added to the numerical scheme to stabilise numerical oscillations (de Almeida et al., 2012). The particular value of $\theta$ used in the simulations is selected as the maximum (i.e. closest to unity) that provides solutions free from spurious numerical oscillations. The subindex $i$ denotes the centre of a computational cell and $i-1 / 2$ and $i-3 / 2$ the three cell interfaces used by the numerical scheme to compute flow discharges in the $x$ direction. The superindex $\eta$ and $\eta+1$ denote the indices of two time steps of the computation. Water depths inside cells are subsequently updated by substituting these flows into the discretized mass conservation equation (Eq. 1):

$y_{i, j}^{\eta+1}=y_{i, j}^{\eta}+\frac{\Delta t}{\Delta x}\left(q_{i-\frac{1}{2}}^{\eta+1}-q_{i+\frac{1}{2}}^{\eta+1}+q_{j-\frac{1}{2}}^{\eta+1}-q_{j+\frac{1}{2}}^{\eta+1}\right)$

where the subindex $j$ is used to denote the $y$ position of the centre of the cell. The stability is controlled by the Courant-Freidrichs-Levy conditions (e.g. Cunge et al., 1980) for shallow water flows:

$C_{r}=\frac{\lambda \Delta t}{\Delta x}$

where the dimensionless Courant Number $\left(C_{r}\right)$ needs to be less than 1 for stability and $\lambda=\sqrt{g h}$ is the wave celerity for the simplified inertial formulation. Equation (6) provides a necessary but not sufficient condition for model stability, and the model estimates the time step as:

$\Delta t=\alpha \frac{\Delta x}{\sqrt{g h_{\max }}}$

where $h_{\max }$ is the maximum depth within the computational domain and $\alpha$ is a coefficient that provides a further limitation on the maximum time step. The current version of the model uses a default value for $\alpha$ of 0.7 , although this can be tuned by the user. Further details of the model can be found in Bates et al. (2010) and de Almeida et al. (2012) and de Almeida and Bates (2013).

\subsection{Model applications}

In order to evaluate scale and roughness effects on urban surface flood modelling, different resolution DEMs produced from terrestrial LiDAR data and Manning's $n$ data were prepared before applying the new inertial model (de Almeida et al., 2012). For the DEM data, $50 \mathrm{~cm}$ and $1 \mathrm{~m}$ resolution DEMs were derived based on the $10 \mathrm{~cm}$ resolution terrestrial LiDAR DEM which was used as the benchmark terrain. Figure 3 shows that significant information (e.g. kerb and road surface camber) contained within the $10 \mathrm{~cm}$ terrestrial LiDAR DEM is lost when degrading to $1 \mathrm{~m}$. The steepness of the kerbs is reduced gradually and road surface camber is smoothed progressively as the resolutions drops to $1 \mathrm{~m}$. Representing these types of small scale features (i.e. walls, kerbs, steps, road camber) in the DEM can have significant impact especially on surface flooding in urban areas (Djokic and Maidment, 1991; Hunter et al., 2008; Fewtrell et al., 2011; Sampson et al., 2012). By contrast, Sampson et al. (2012) show that micro scale terrain features such as kerbs are not typically captured in airborne LiDAR data.

In previous studies on this test case (Fewtrell et al., 2011; Sampson et al., 2012), a single fixed composite friction coefficient was used $(n=0.035)$ for the whole area due to large oscillations in the solution which arose at more realistic friction values when using the Bates et al. (2010) numerical solution for Eq. (2). This value $(n=0.035)$ is likely to be too high to properly represent urban skin friction conditions. In this study, we applied to the models two types of friction coefficient, namely distributed Manning's $n$ and a single composite friction coefficient for the entire domain (Fig. 4). Distributed Manning's $n$ data were derived using UK Ordnance Survey (OS) MasterMap ${ }^{\circledR}$ vector data. The derived data were then checked by reference to Google ${ }^{\odot}$ satellite 


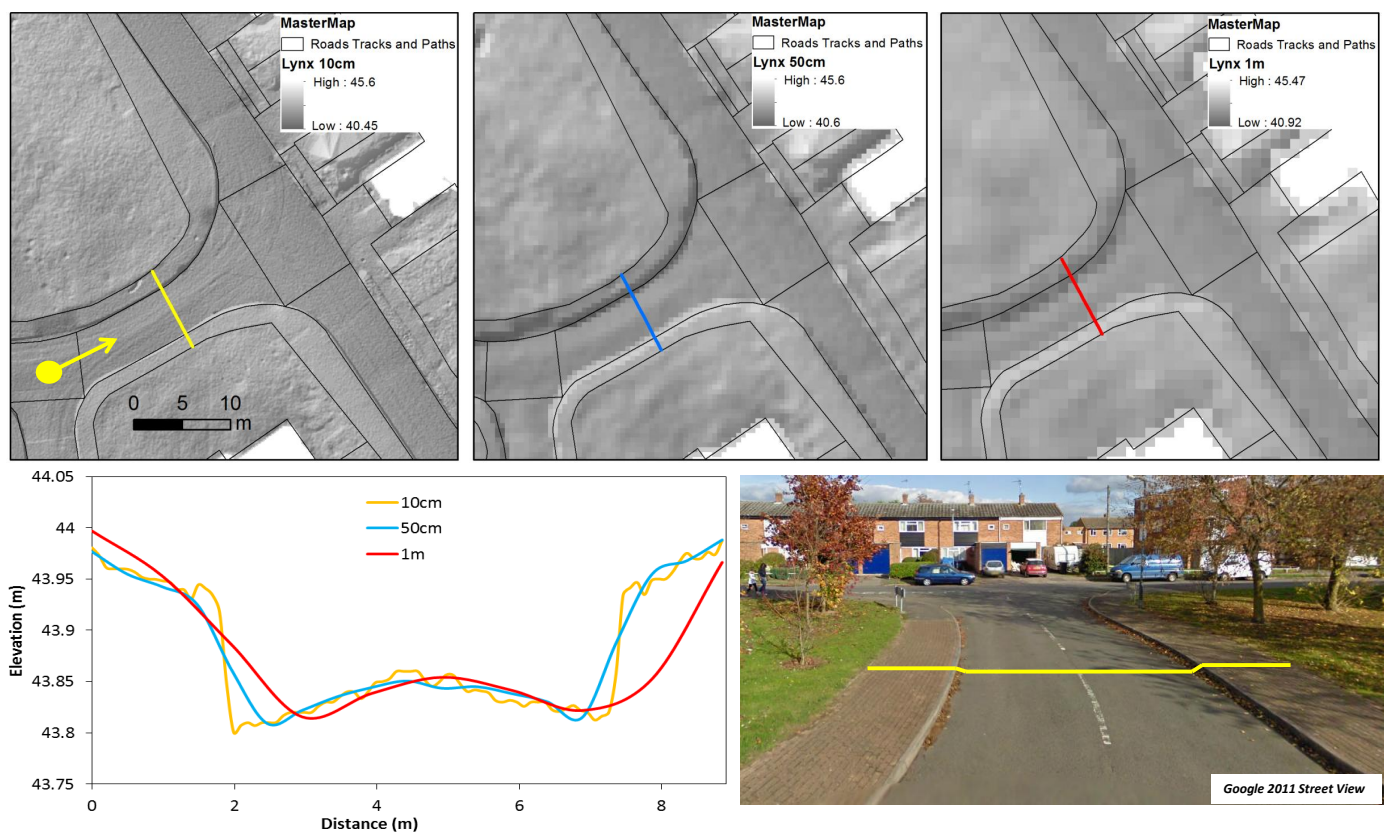

Fig. 3. Google street view and street cross-sections showing the variation in kerb and road surface camber representation on the $10 \mathrm{~cm}$ and derived $50 \mathrm{~cm}$ and $1 \mathrm{~m}$ terrestrial DEMs.

(a)

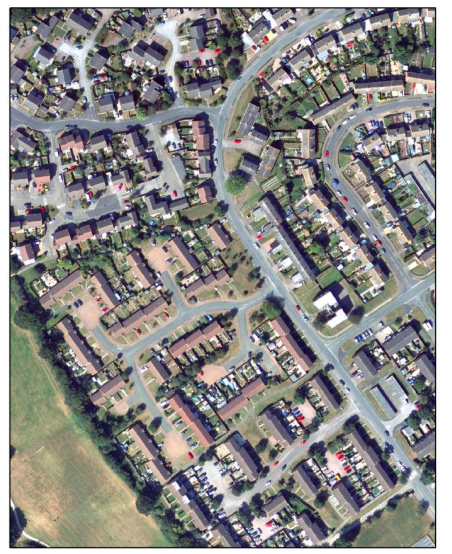

(b)

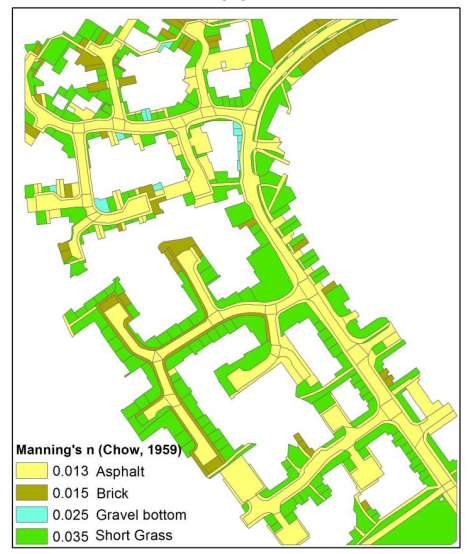

(c)

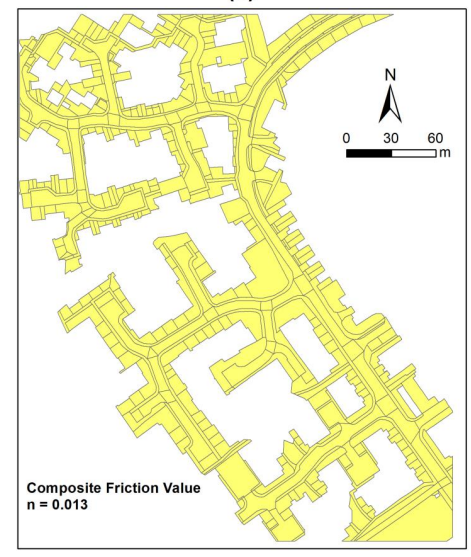

Fig. 4. Land use classification and Manning's $n$ value distribution (a) Google ${ }^{\circledR}$ satellite image (b) distributed Manning $n$ value (c) single composite friction value.

images and Google ${ }^{\odot}$ street view, and any misclassified areas (such as grass classified as pavement in the MasterMap ${ }^{\circledR}$ data) were manually corrected. Manning's $n$ values taken from the standard Chow (1959) table were assigned to every type of land use and then converted to $10 \mathrm{~cm}, 50 \mathrm{~cm}$ and $1 \mathrm{~m}$ raster data using the cell centred method. As shown in Fig. 4, Manning's $n$ values of $0.013,0.015,0.025$ and 0.035 were assigned to asphalt road, brick, gravel and short grass surfaces respectively. During the data-processing stage buildings and other high features are marked as "no-data" pixels that function as impermeable boundaries, ensuring that such features are excluded from the DEM. The second type of friction parameterization is a uniform composite, assigned to the whole domain, for which the value of $n=0.013$ was chosen because it represents the smooth and impervious road surfaces that typically underlie flow paths taken by surface flood water in urban areas.

In order to evaluate the different resolution terrestrial LiDAR DEM and roughness conditions, we used the new inertial formulation of LISFLOOD-FP (de Almeida et al., 2012, Eq. 4) to simulate the urban inundation test case in Alcester, UK. The improvement introduced by this new scheme is particularly relevant in situations involving low friction surfaces, where the previous scheme (Bates et al., 2010) exhibited 
(a)

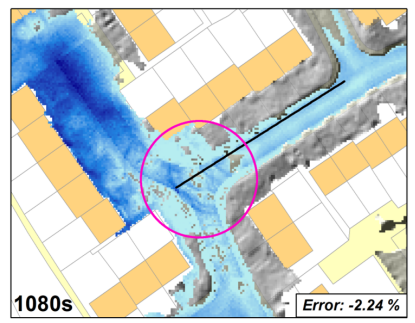

(b)

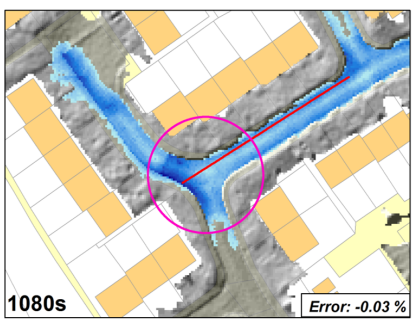

(c)

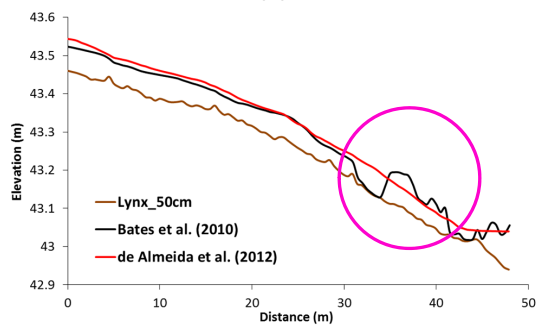

Fig. 5. (a) Simulation result at $t=1080 \mathrm{~s}$ using inertial formulation Bates et al. (2010). (b) Simulation result at $t=1080 \mathrm{~s}$ using inertial formulation de Almeida et al. (2012), (c) water surface profiles with original $50 \mathrm{~cm}$ terrestrial LIDAR DEM surface.

problems of numerical stability which can introduce additional problems of mass balance to the model. In particular, in shallow parts of the computational domain these unphysical oscillations can lead to negative values of the water depth. The current implementation of the model handles this situation by resetting the negative values to zero so that the model can proceed to the next time step. This artificially adds water into the domain, causing mass balance errors to grow. The comparison of the mass balance error (difference between the net inflow through the boundaries and the change in the water volume within the domain) in different simulations can actually be used as a first indicator of numerical stability. The previous inertial formulation developed by Bates et al. (2010) was initially compared to that by de Almeida et al. (2012) on the $50 \mathrm{~cm}$ LYNX DEM and one single composite low friction $(n=0.013)$ conditions. The results obtained with the former showed non-negligible numerical oscillations (see Fig. 5) and high per time step volume error $-2.24 \%$. Using the same parameters, the new improved inertial scheme (with $\theta=0.8$ ) was applied to the test site. This new formulation produced an oscillation free solution with much reduced per time step volume error $(-0.03 \%$. All the simulations for the paper were run using $\alpha$ of 0.7 for the time step limiter (i.e. Eq. 7), for $2 \mathrm{~h}$ of simulated time ( $30 \mathrm{~min}$ of inflow event followed by $90 \mathrm{~min}$ for the water in the domain to come to steady state).

Even though this study uses values of Manning's coefficient that are relatively low, only subcritical flow conditions are observed in all simulations as a consequence of the relatively flat topography. The results of the simulations have shown that the Froude number $F r=u / \sqrt{g h}$ (where $u$ is the magnitude of the velocity vector) is smaller than 0.6 over most of the domain during all stages of the flood propagation, which ensures that the model's assumptions introduce minimum errors (de Almeida and Bates, 2013).

\section{Results and discussion}

\subsection{Overview of simulations}

Initially, two configurations (fixed and distributed Manning's $n$ ) of the new inertial model were built for each DEM grid scale $(\Delta x=10 \mathrm{~cm}, 50 \mathrm{~cm}$ and $1 \mathrm{~m})$ to establish the variability associated with changing resolution and different surface friction conditions. Model prediction of water depths, flood extent and flow velocity were evaluated against the relevant benchmark high-resolution (10 cm terrestrial LiDAR DEM) simulations using root-mean-square differences (RMSD) and fit $\left(F^{2}\right)$ statistic (Werner et al., 2005). Figure 6 shows the propagation of the flood wave over the $10 \mathrm{~cm}, 50 \mathrm{~cm}$ and $1 \mathrm{~m}$ terrestrial LiDAR DEMs for different roughness conditions at four times $(9,24,36,120 \mathrm{~min})$ using the new inertial formulation. In all simulations, the domain is initially dry and water enters at the simulated blocked drain in the northeast corner and flows down the main north-south aligned street. During the early stages of the simulations ( $t=9 \mathrm{~min}$ ), water passes the first side street, which is perpendicular the main road, without flowing down it, continuing instead in a southeasterly direction. The wave front initially propagates alongside kerbs due to the representation of the road camber in the DEM, with water only spreading across the entire width of the road as water depths increase. The kerbs also serve to prevent water from spilling off the road and towards adjacent properties until the water depth is sufficient to exceed the kerb heights. This simulated behaviour is due to the retention of the road camber within the DEM, demonstrating the importance and representation capability of very high resolution DEMs in surface water flood modelling. When the flood wave reaches the second road junction, the road surface gradient causes some water to spread along the side street which runs in a southwesterly direction, whilst the remainder continues to flow along the main road which lies in a southeasterly direction (Fig. 6, $t=24 \mathrm{~min}$ ). As the simulations progress, water depths are seen to increase at the end of second and last southern perpendicular streets, which are areas of ponding caused by blocking at the boundaries of the DEM. While some areas of ponding are caused simply by depressions in the DEM, others occur at the boundaries of the 

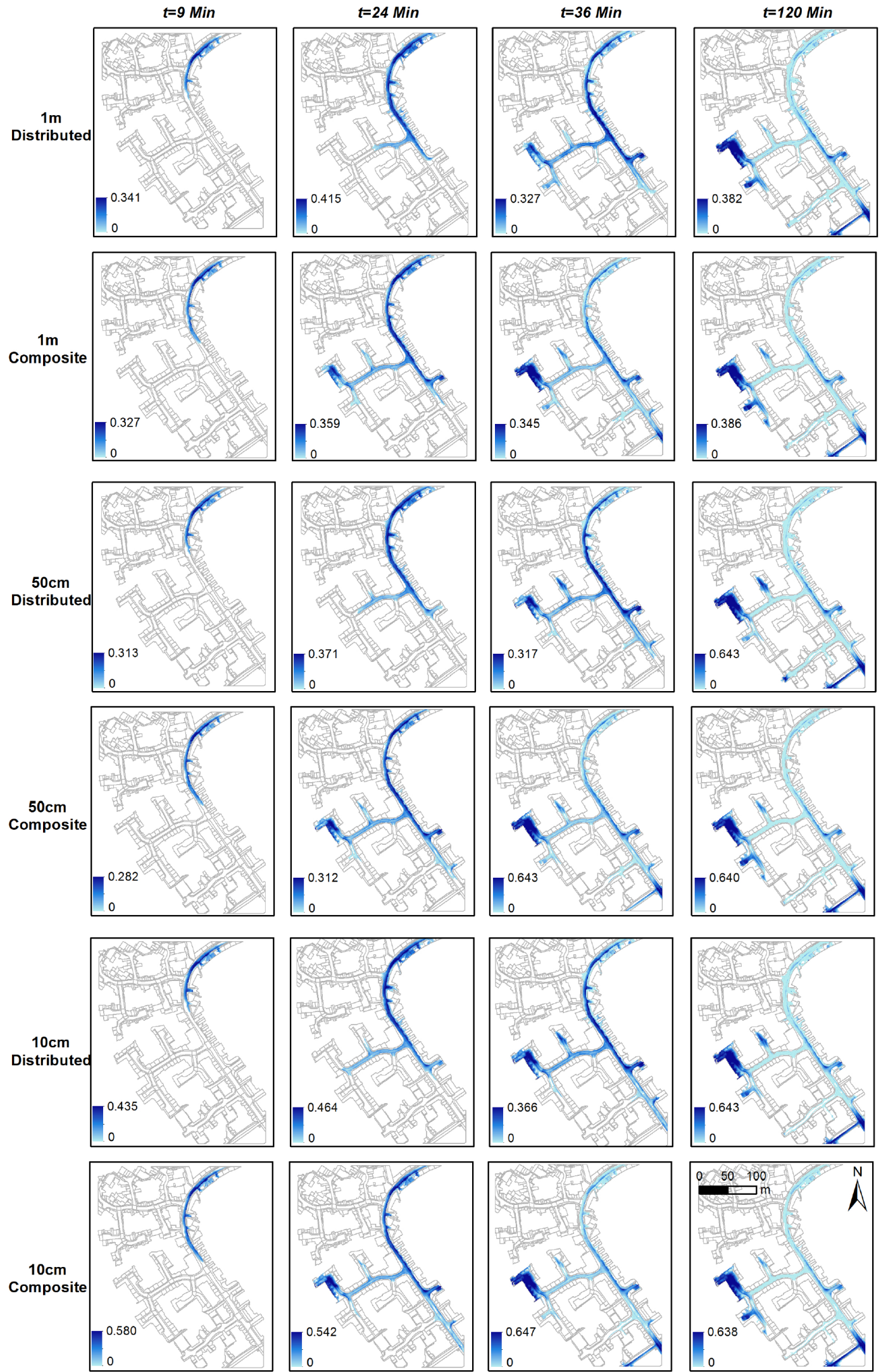

Fig. 6. Progression of surface flooding predicted by different resolution and roughness conditions using the new inertial formulation. 

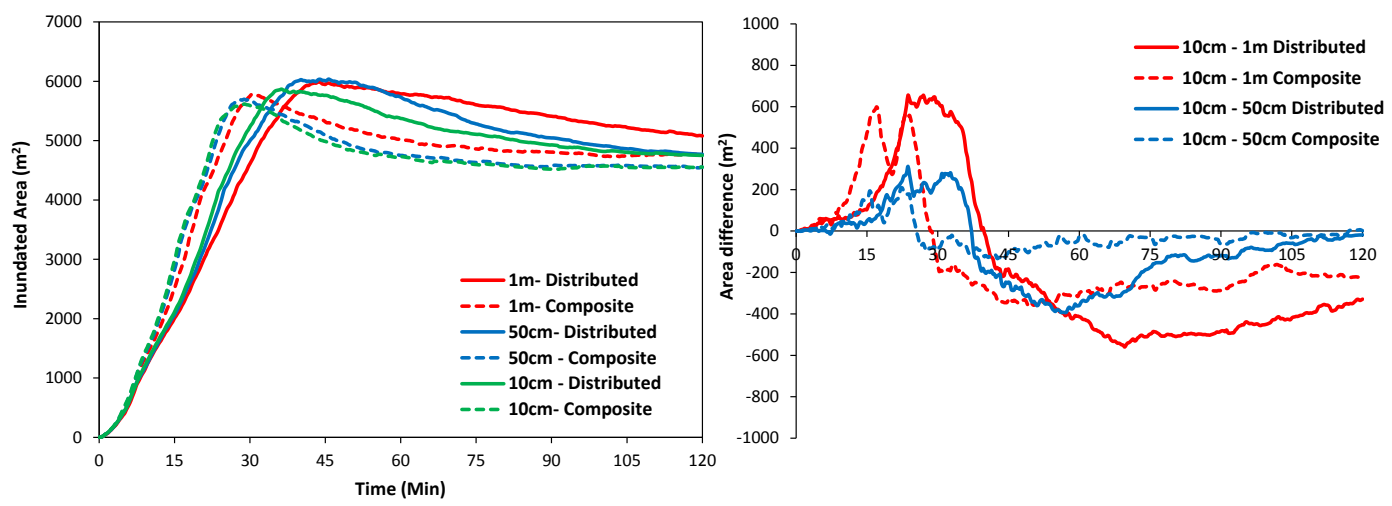

Fig. 7. Predictions of inundated area and differences based on $10 \mathrm{~cm}$ models through time with different resolutions and roughness conditions.

DEM that are specified as being closed in this model. The impact of road cambers being correctly represented in the terrestrial LiDAR DEM can also be seen clearly at $t=36$ and $120 \mathrm{~min}$, where water advancing in a southwesterly direction down the second wetted side street flows along the road edges due to the convex profile of the road surface. Finally, water continues to drain into the ponded areas until a near steadystate $(t=120 \mathrm{~min})$ is reached.

\subsection{Sensitivity to model resolution and surface friction parametrization}

As the flood wave propagates through the street network, differences develop in the simulated water depths and inundation extent between the distributed and composite friction conditions and different resolution DEMs. Maximum water depths increase $\sim 37 \%$ when the model resolution increases from $1 \mathrm{~m}$ to $10 \mathrm{~cm}$ and surface water speeds are reduced when using distributed friction conditions. Surface water inundation is more rapid with a composite friction $(n=0.013)$ and finer resolution models (Fig. 6). This latter result is opposite to the findings of Yu and Lane (2006a) for urban areas using an airborne LiDAR DEM, and occurs due to rapid propagation of water along "channels" that form at the road edge as a result of the road camber and roadside kerbs. These 'channels' are smoothed as resolution decreases, and consequently water depths and velocities within them are greater on the $10 \mathrm{~cm}$ DEM ( $\sim 37$ and $\sim 32 \%$ respectively) than the $1 \mathrm{~m}$ DEM. A set of idealised tests was performed in order to confirm that the above differences are a result of the fine scale topography, rather than potential structural errors introduced by the model. These test cases consist of simulating the flow of a fixed volume of water, originating from a fixed point, down an idealised road represented by a long and straight surface of uniform slope, rectangular cross section and Manning's $n$ of 0.013 . These tests were run at $10 \mathrm{~cm}$, $50 \mathrm{~cm}$ and $1 \mathrm{~m}$ resolutions for $60 \mathrm{~s}$. The results of these tests have shown that the distance travelled by the wave front from the fixed point of origin varied by only $\sim 1 \%$ between the three resolutions. This provides a strong evidence that the results obtained on the Alcester DEM above are not an artefact of model structure, but rather are the consequence of the ability of fine resolution DEMs to represent hydraulically relevant surface features. This is also supported by previous tests performed by Bates et al. (2010) and de Almeida and Bates (2013) at different resolutions. The simulations presented in this paper are therefore grid independent in what concerns to model structure (also supported by Bates et al., 2010), so that the main differences between the results at different resolutions can be directly associated with the representation of topography. The increased speed of wave propagation across the domain with the fixed Manning's $n$ of 0.013 relative to the distributed friction map is unsurprising as an increase in surface friction will reduce flow velocities; however it is interesting to note that later in the simulation the inundation extent is greater in models using distributed friction as the water is retained for longer (Fig. 7). Therefore, during inflow to the domain, the inundated area is larger in all models which use a single composite friction due to higher propagation speeds; after the inflow has ended the inundated area becomes greater in the models which use distributed friction maps. In terms of maximum inundation extent, when the model resolution is increased $(1 \mathrm{~m}$ to $10 \mathrm{~cm})$, the inundation extent is decreased by $\sim 3 \%$ in composite friction models and $\sim 6 \%$ in distributed models in this test case. The area difference plot in Fig. 7 clearly demonstrates the effects of both grid resolution and friction parametrization on water propagation across the domain. During the inflow period $(t<30 \mathrm{~min})$, the inundation area is greater in high resolution models employing the composite friction map as water propagates across the DEM more quickly under these conditions. After the inflow period this pattern is reversed, as water drains to depressions in the DEM (thus reducing inundation area) more quickly in the same high resolution models employing the composite friction map.

Figures 8 and 9 show the evolution of water depths and elevations, and the effects of different roughness, at four control points (see Fig. 1) through the simulation using 


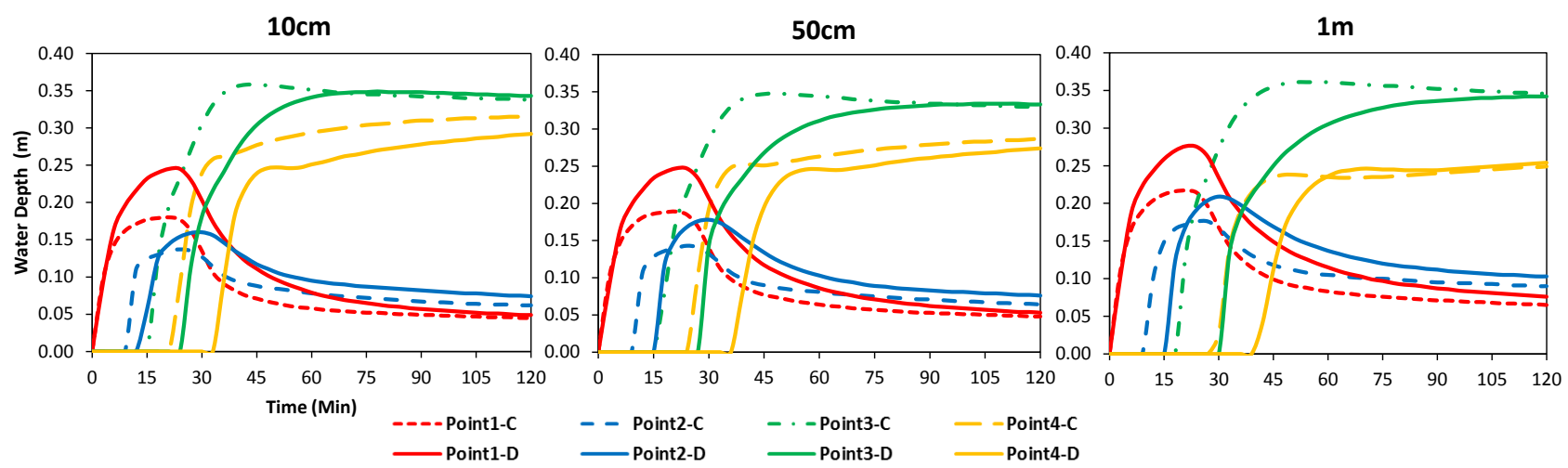

Fig. 8. Profiles of simulated water depth through time at the four control points at $\Delta x=10 \mathrm{~cm}, 50 \mathrm{~cm}$ and $1 \mathrm{~m}$ using Composite $(C)$ and Distributed $(D)$ roughness conditions.
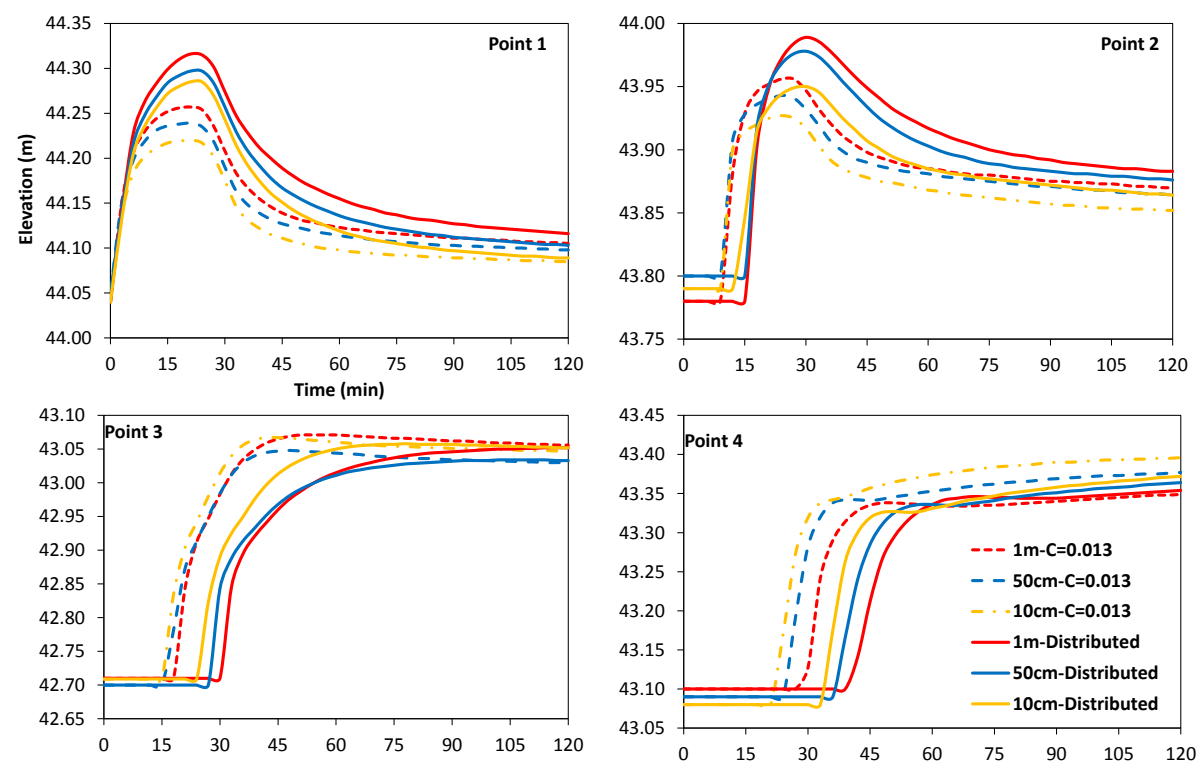

Fig. 9. Profiles of simulated water elevation through time at the four control points at $\Delta x=10 \mathrm{~cm}, 50 \mathrm{~cm}$ and $1 \mathrm{~m}$ using Composite $(C)$ and Distributed roughness conditions.

composite and distributed friction conditions at grid resolutions of $10 \mathrm{~cm}, 50 \mathrm{~cm}$ and $1 \mathrm{~m}$. Point 1 represents an area of rapid flow where water runs down a steep section of road, point 2 represents a junction where water flow splits between two streets, and points 3 and 4 are areas where ponding occurs. The water depths are higher in models using distributed roughness conditions at points $1(\sim 23 \%)$ and $2(\sim 13 \%)$, but the opposite is observed after approximately $30 \mathrm{~min}$ at points 3 and 4 where the models using composite friction exhibit greater water depths and elevations with $\sim 15$ and $\sim 17 \%$ increases respectively. This difference occurs as the wave propagates faster when the low composite friction value $(n=0.013)$ is used, enabling water to reach the boundary of the DEM and pond earlier. These differences in arrival time between the distributed and composite friction models can be seen at points 2 to 4 in Figs. 8 and 9. Time delay in the distributed roughness models (relative to the composite models) reaches $12 \mathrm{~min}$ in this test case, despite the farthest points (3-4) being located only $300 \mathrm{~m}$ from the inflow point. For the distributed and composite friction configurations arrival times increase as resolution decreases, with a similar increase in time delay between the friction configurations also being observed. For instance, when using the composite friction model, arrival time to point 4 is $24 \mathrm{~min}$ at $10 \mathrm{~cm}$ resolution, increasing to $30 \mathrm{~min}$ at $1 \mathrm{~m}$ resolution. For the distributed friction model, surface water reaches point 4 in $36 \mathrm{~min}$ at $10 \mathrm{~cm}$ resolution, increasing to $42 \mathrm{~min}$ for the $1 \mathrm{~m}$ model. It should also be noted from Fig. 8 that, despite representing flows resulting from a 1 -in-200 yr rainfall event, simulated water depths in areas of ponding along streets do not exceed the $0.5 \mathrm{~m}$ threshold that represents the minimum depth associated with vehicle damage (Wallingford, 2006). 

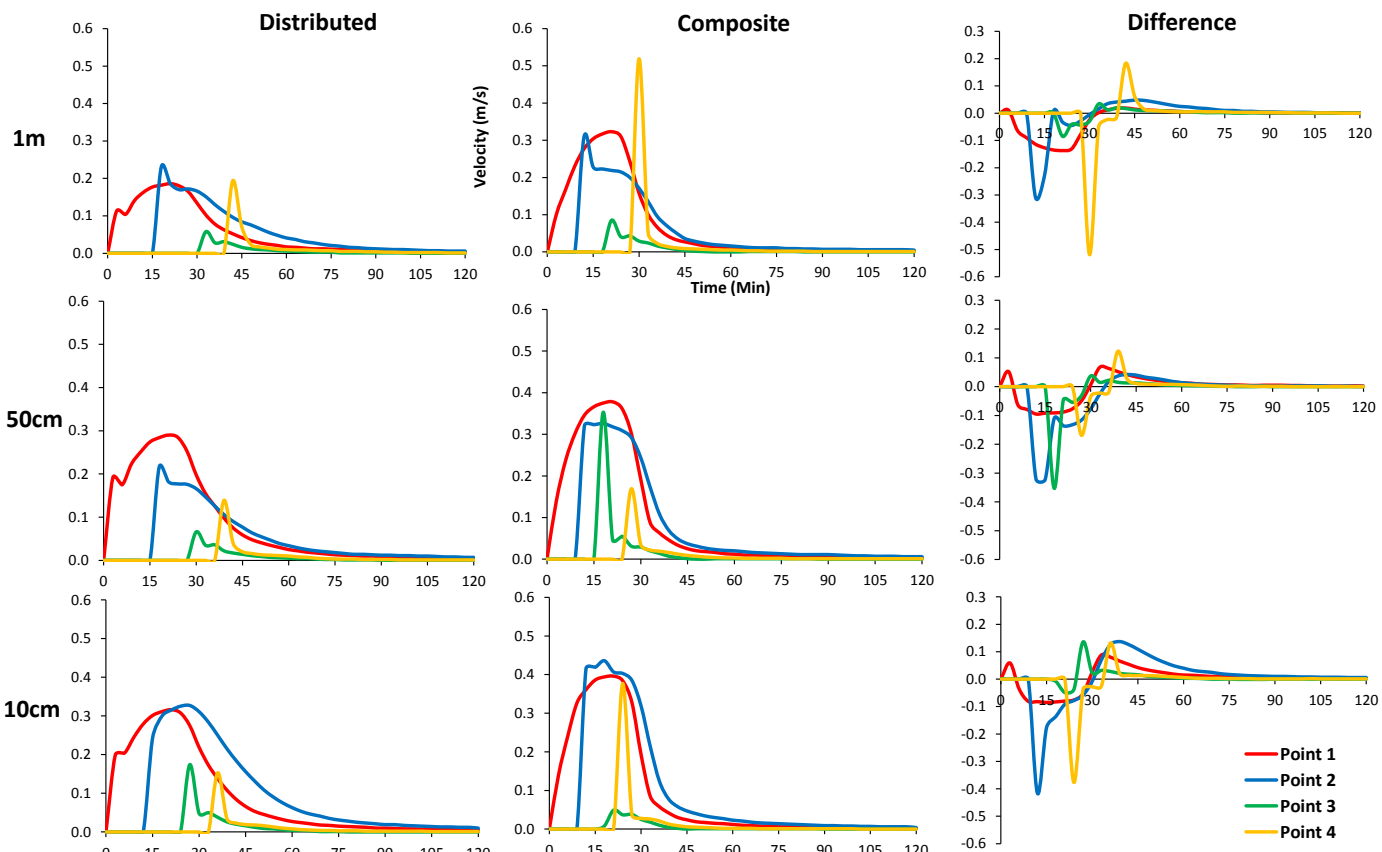

Fig. 10. Simulated velocity over time at the four control points across the different resolutions using distributed and composite frictions and difference plots (distributed minus composite). (All $y$ axes show velocity as $\mathrm{m} \mathrm{s}^{-1}$, all $x$ axes show time as minute.)

As such, the flows under discussion in this paper are all shallow in nature, allowing them to be influenced significantly by detailed surface topography.

Danger to people, vehicles, buildings and some infrastructure are assessed using the concept of flood hazard, which can be expressed as a combination of not only water depth but also velocity (Kok et al., 2005; Kelman and Spence, 2004; Jonkman and Kelman, 2005; Wallingford, 2006; Apel et al., 2009; Xia et al., 2010, 2011). Therefore, in addition to the flood depth, velocity prediction is a valuable addition to flood studies. Fewtrell et al. (2011) and Neal et al. (2011) suggested that the simplified models coded in LISFLOODFP can be used for velocity simulation for a wider range of conditions than previously thought due to the inclusion of stringent stability conditions. Figure 10 shows the evolution of the velocity at the four points throughout the simulation at each resolution for both distributed and composite friction parameters. Velocity is calculated as the square root of the sum of the velocities in the $x$ and $y$ directions squared and hence purely represent the scalar velocity. In the models using the composite friction condition and the finer resolution DEM, velocities are typically greater $(\sim 15$ and $\sim 25 \%)$ than models using distributed friction conditions and the coarser resolution DEM. Decrease in arrival time of peak velocity can be seen at point 3 and 4 in each resolution under distributed friction conditions. These differences can be clearly summarized by comparing velocities from the $1 \mathrm{~m}$ distributed model to the $10 \mathrm{~cm}$ composite model in Fig. 10. In the $1 \mathrm{~m}$ distributed model, velocities are low and the timings of peak velocities are clearly distinct and dependent on the distance of the control point from inflow point. In the $10 \mathrm{~cm}$ composite model, velocities are high and thus separation of peak velocities is greatly reduced, almost to the point of overlap.

\subsection{Global model performance measures}

In order to analyse the global effect of model resolution on simulation results, the root-mean-squared difference (RMSD) between coarse models $(50 \mathrm{~cm}$ and $1 \mathrm{~m})$ and the benchmark high resolution $(10 \mathrm{~cm})$ models for distributed and composite roughness conditions are computed for depth and velocity (Fig. 11); in addition the fit statistic $\left(F^{2}\right.$, Werner et al., 2005) is calculated for inundated area. $50 \mathrm{~cm}$ and $1 \mathrm{~m}$ composite models are compared to the $10 \mathrm{~cm}$ composite benchmark and $50 \mathrm{~cm}$ and $1 \mathrm{~m}$ distributed models are compared to the $10 \mathrm{~cm}$ distributed benchmark. There is a detectable reduction in model performance at coarse resolution which was previously noted by Horritt and Bates (2001), Yu and Lane (2006a) and Fewtrell et al. (2008, 2011). In this test case, RMSD is typically higher and $F^{2}$ is lower in the $1 \mathrm{~m}$ models than in the $50 \mathrm{~cm}$ models, both in terms of water depth and velocity over the simulation period. In terms of distributed and composite roughness conditions, RMSDs of water depth are lower (by $\sim 12 \%$ ) in the models using composite friction parameters at a given resolution. The difference in $F^{2}$ between distributed and composite friction parameters is typically greater at $1 \mathrm{~m}$ than at $50 \mathrm{~cm}$, especially during the early dynamic stages of the simulation while inflow is occurring. In the case of the RMSD of velocity, a 

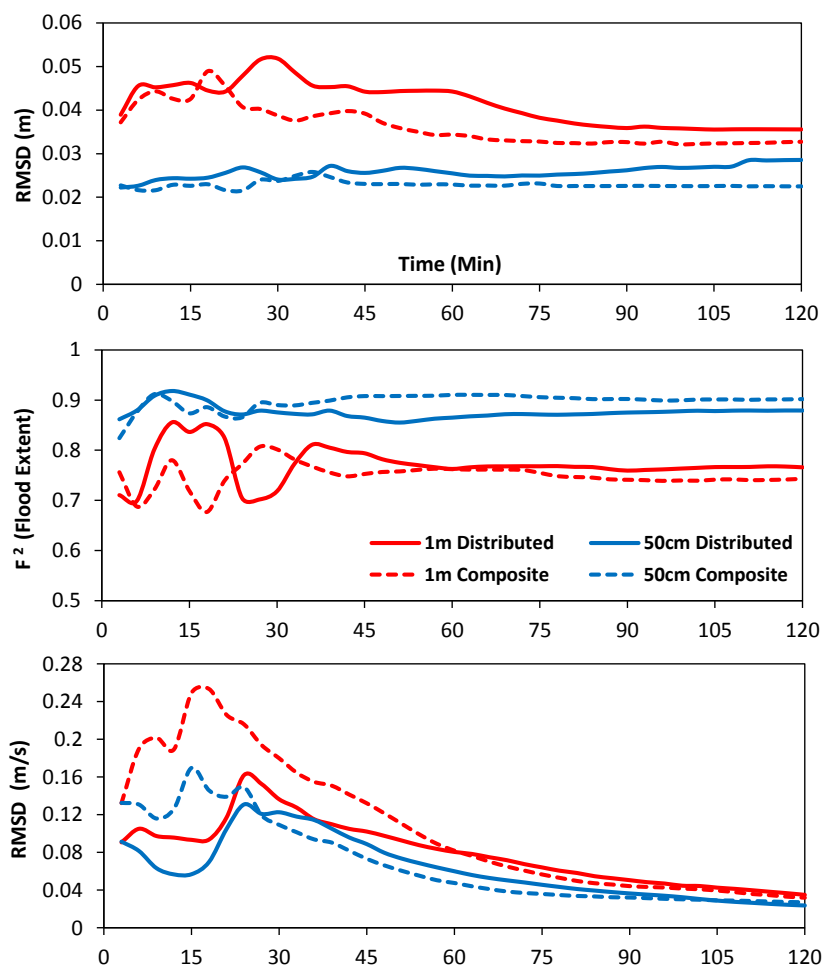

Fig. 11. Evolution of the root-mean-squared difference (RMSD) and $F^{2}$ between the benchmark $\Delta x=10 \mathrm{~cm}$ models with distributed and composite roughness and the coarser $50 \mathrm{~cm}$ and $1 \mathrm{~m}$ models throughout the simulation for the water depth and velocity.

smooth distribution is not seen as with the RMSD of water depth. The RMSDs of velocity are typically lower $(\sim 32 \%$ at $1 \mathrm{~m}$ and $\sim 8 \%$ at $50 \mathrm{~cm}$ ) in the models using distributed roughness parameters during the early stages of the simulation, a finding that contrasts with the RMSDs of the water depth during this period.

The above analysis has shown that modelled water depths, inundation areas and velocities all exhibit sensitivity to friction parametrization and changes in DEM resolution, even when the resolution of the coarsest DEM employed here $(1 \mathrm{~m})$ exceeds that typically used in urban inundation studies (Mason et al., 2007; Brown et al., 2007; Fewtrell et al., 2008; Hunter et al., 2008; Gallegos et al., 2009; Neal et al., 2009). The results have shown water to propagate most quickly across the highest resolution DEM as small scale topographical features such as road camber and street kerbs encourage the formation of small connecting "channels" that rapidly convey water across the domain. As reducing the resolution from $10 \mathrm{~cm}$ to $1 \mathrm{~m}$ smoothes these features and slows down wave propagation, an attempt to recover the $10 \mathrm{~cm}$ result on the $1 \mathrm{~m}$ grid will require reduced surface friction to compensate for the loss of connectivity. This contrasts with previous studies undertaken at coarser grid scales using airborne LiDAR data, where micro scale topographical features cannot be represented and where decreasing grid resolution led to faster wave propagation. In these previous studies the terrain smoothing effect of decreasing DEM resolution (Yu and Lane, 2006a) could potentially be compensated for by increasing surface friction. To test whether decreasing surface friction could potentially achieve the same effect here, the $1 \mathrm{~m}$ models were re-run with surface friction values of 50 and $1 \%$ of the original distributed and composite values, with the results evaluated in terms of differences in water depth, arrival time, RMSD and inundated area from the benchmark $10 \mathrm{~cm}$ models (Fig. 12). The results show that even when employing the most extreme $1 \%$ surface friction scheme (spatially uniform $n=0.00013$ ), the coarse $1 \mathrm{~m}$ model was unable to compensate for the reduced connectivity and recover the water depth, arrival time or inundated area of the fine $10 \mathrm{~cm}$ benchmark model. The low sensitivity of the model results to further reductions of the friction coefficient suggests that the previous values were already too low and the friction term too small compared to other terms in the governing equations (including potentially error terms introduced by the numerical scheme). Furthermore, the RMSD of the 50 and $1 \%$ friction models is increased over the standard model during later stages of the simulation, suggesting that this approach adversely affects the distribution of final water depths across the domain. These results suggest that, when modelling shallow water flows such as those associated with urban surface water flooding, the ability of very high resolution DEMs to represent hydraulically relevant micro-topographic features (e.g. kerbs, road camber, wall, etc.) has a significant impact on flow propagation that cannot be recovered at coarser grid scales through surface friction parametrization alone. Instead, we need to develop optimal ways to include hydraulically relevant information about micro scale topographic features in coarser DEMs as for the foreseeable future decimetric resolution hydraulic models of whole city regions may be computationally prohibitive.

\subsection{Model stability and runtime analysis}

With regard to model stability, Bates et al. (2010) highlighted that care should be taken when using the inertial formulation for large areas where low surface friction dominate due to increased instabilities, which represented an important obstacle for the application of this equation set for modelling flow in urban areas. However, the new formulation proposed by de Almeida et al. (2012) considerably reduces spurious oscillations and mass errors on the finer resolution DEMs (i.e. 50 and $10 \mathrm{~cm}$ ) and under low friction conditions. In our simulations this was achieved by adding a relatively small amount of numerical diffusion to the method (e.g. $\theta$ between 0.9 and 0.7). The computational cost of running the simulation under distributed or composite friction conditions was similar. As expected, changing the resolution had a significant impact on computational time. Runtimes for the 1-in$200 \mathrm{yr}$ event at $10 \mathrm{~cm}, 50 \mathrm{~cm}$ and $1 \mathrm{~m}$ scales for $0.1 \mathrm{~km}^{2}$ area were typically $\sim 90 \mathrm{~h}, \sim 21 \mathrm{~min}$ and $\sim 5 \mathrm{~min}$ respectively 

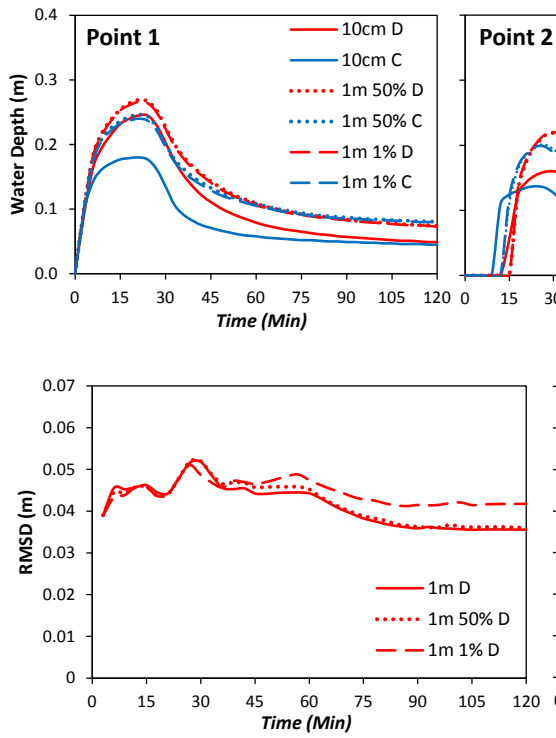
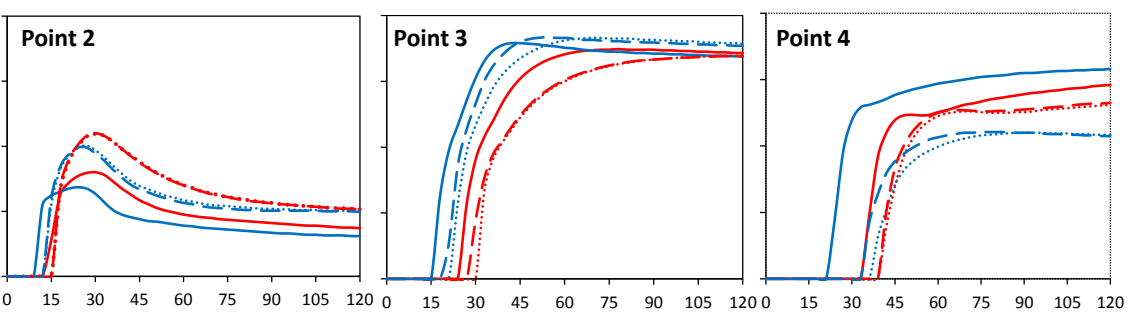

(a)

(b)

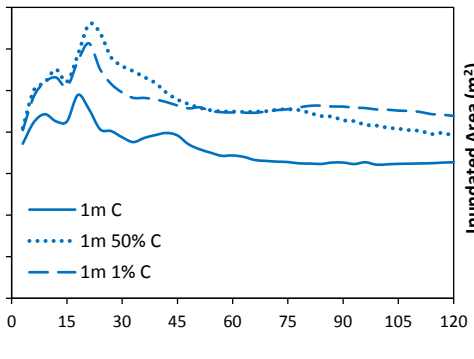

(b)

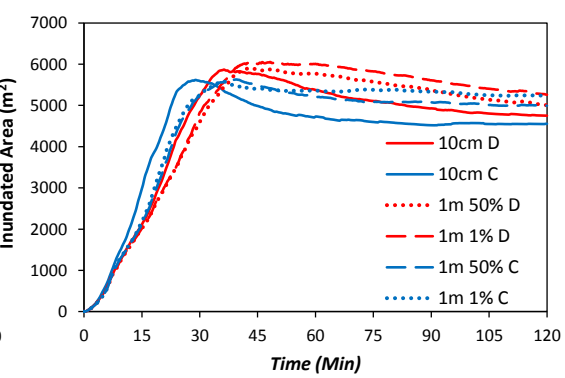

(c)

Fig. 12. (a) Comparison of simulated water depth through time at the four control points between $10 \mathrm{~cm}$ models using distributed $(D)$ and composite $(C)$ friction and $1 \mathrm{~m}$ models using 50 and $1 \%$ of distributed and composite friction values. (b) Comparison of RMSD through time between the benchmark $10 \mathrm{~cm}$ models with distributed $(D)$ and composite $(C)$ friction and the 1 m models using 100,50 and $1 \%$ of distributed and composite values. (c) Comparison of inundated area between benchmark $10 \mathrm{~cm}$ models using distributed and composite friction and $1 \mathrm{~m}$ models using 50 and $1 \%$ of friction values.

using a Quad core Intel Core i7 CPU Q740 1.73 GHz processor. Hence, as previously noted by Sampson et al. (2012), the current version of LISFLOOD-FP would not be appropriate for large-scale urban flood modelling using very fine resolution DEMs of $10 \mathrm{~cm}$ or below. There is increasing interest in undertaking hydraulic modelling over very large domains (Pappenberger et al., 2009; Merz et al., 2010), and continued development of efficient hydraulic code, as well as methods for efficient use of topographic data, will be required to achieve this aim.

\section{Conclusions}

This paper presents applications and benchmark testing results of a new inertial formulation of LISFLOOD-FP using distributed and composite friction conditions on high resolution terrestrial LiDAR DEMs $(10 \mathrm{~cm}, 50 \mathrm{~cm}$ and $1 \mathrm{~m})$ in Alcester, UK. This represents the first attempts at conducting hydraulic modelling using sub-meter scale $(10 \mathrm{~cm}, 50 \mathrm{~cm}$ and $1 \mathrm{~m}$ ) elevation data derived from terrestrial LiDAR data in conjunction with realistic friction conditions $(n<0.03)$. The water depth, inundation extent, arrival time and velocity predicted by the simulations were shown to vary in response to DEM resolution and different friction conditions. Maximum water depths and velocity are shown to increase by up to $\sim 37$ and $\sim 32 \%$ respectively with increasing DEM resolution, whilst inundation extent is shown to decrease by approximately $6 \%$. A further idealised simulation is used to confirm that the results are grid independent and due to the ability of terrestrial LiDAR to resolve small scale features missed by airborne LiDAR due to its use of a sideways looking laser system with $\sim 1-3 \mathrm{~cm}$ point spacing. During a surface flooding event, the formation of flow 'channels' constrained by small scale features such as road cambers and kerbs is observed in simulations run on the fine scale terrestrial LiDAR DEMs. These channels improve hydraulic connectivity across the domain, allowing water to drain rapidly to depressions where ponding occurs.

In order to investigate the effects of surface roughness parametrization, two surface friction configurations (a uniform composite value and a variable distributed friction map) were applied to all resolution DEMs of the Alcester test site and the impact on flood depth, flood extent, flood arrival times and velocity were evaluated. Land use classes for friction conditions were derived from UK Ordnance Survey (OS) MasterMap $^{\circledR}$ data with some editing using Google ${ }^{\circledR}$ satellite images and Street View. The results showed flood extent to be less sensitive to surface friction configuration than water depths and velocities. Flood wave arrival time is particularly sensitive to the specification of surface friction parameters, a finding that agrees with previous studies showing flood velocity and wetting-front speeds to be sensitive to resistance parameter distributions (Mason et al., 2003; Begnudelli and Sanders, 2007). However, recovering the result of the finest grid resolution simulation on the coarser DEM by changing the surface friction is shown not to be possible at this site. 
This is because flow propagation at the finest grid resolution is not only related to the surface friction values but also to the representation of hydraulically relevant small scale topographical features in the DEM. Reducing the resolution of the DEM reduces the capacity to represent these features and leads to a loss in modelling hydraulic connectivity across the domain, something that cannot here be compensated for by changing the surface friction parametrization. We conclude that micro scale terrain features are therefore relatively more important to flood wave development because they create or block flow pathways rather than because they generate frictional losses.

The new numerical solution for the Bates et al. (2010) equations proposed by de Almeida et al. (2012) demonstrated increased model stability on high resolution DEMs under low friction conditions $(n=0.013)$ compared to the previous scheme, although it reduced computational efficiency at $10 \mathrm{~cm}$ resolution. The new formulation was also seen to solve the instabilities caused by low friction conditions on areas with shallow slopes. However, instability can also originate on high gradient slopes where supercritical flow occurs and this may be outside the ability of simpler schemes to simulate as these often strictly apply to subcritical flows only (Neal et al., 2011). Future work should concentrate on increasing the computational performance of simplified shallow water models on finer resolution DEMs ( $10 \mathrm{~cm}$ or below) and improving their ability to simulate supercritical flows for high gradient terrain features which may be common in urban environments.

The paper has shown that fine scale terrain data are required for the simulation of shallow surface water flows in urban environments. This finding suggests that terrestrial LIDAR would be beneficial for future urban surface water flood studies where shallow flows occurring across much of the domain must be modelled accurately to enable the correct identification of areas where water is likely to accumulate and reach damaging depths. It will also be beneficial for detailed site-studies where Sustainable Urban Drainage Systems (SUDS) are being considered, as precise simulation of surface water flow will facilitate the planning and implementation of SUDS techniques such as source control, permeable conveyance systems and temporary storm water storage solutions (DEFRA, 2004). A complete SUDS design analysis for a site could not be completed without coupling the model to a sewer model able to represent the typically employed overflow pipe system. An uncoupled model would still be of value at the planning stage to identify areas most at risk from surface water flooding, as well as when considering remedial flood drainage for when the system capacity is exceeded. Unfortunately, simulation at decimetric scales remains computationally expensive even when using efficient state-of-the-art hydraulic models, so it is suggested that future research should focus on further increasing the efficiency of such models as well as developing techniques that enable the representation of key hydraulically relevant small scale features at coarser resolutions.

Acknowledgements. Hasan Ozdemir was funded by TUBITAK (The Scientific and Technological Research Council of Turkey) with program of 2219. The work forms part of Christopher Sampson's PhD research at the University of Bristol funded by a Natural Environment Research Council (NERC) Combined Award in Science and Engineering (NE/H017836/1) in partnership with the Willis Research Network (WRN). The authors would like to thank Paul Smith and James Whitcombe of the Environment Agency Geomatics Group for helping the authors understand LiDAR surveying with LYNX in practice.

Edited by: P. Passalacqua

\section{References}

Apel, H., Aronica, G. T., Kreibich, H., and Thieken, A. H.: Flood risk analyses-how detailed do we need to be?, Nat. Hazards, 49, 79-98, 2009.

Aronica, G. T. and Lanza, J. G.: Drainage efficiency in urban areas: a case study, Hydrol. Process., 19, 1105-1119, 2005.

Aronica, G. T., Tucciarelli, T., and Nasello, C.: 2D Multilevel model for flood wave propagation in flood-affected areas, J. Water Resour. Pl. Manage., 124, 210-217, doi:10.1061/(ASCE)07339496(1998)124:4(210), 1998.

Barnea, S. and Filin, S.: Keypoint based autonomous registration of terrestrial laser point-clouds, ISPRS J. Photogramm. Remote Sens., 63, 19-35, 2008.

Bates, P. D. and De Roo, A. P. J.: A simple raster-based model for flood inundation simulation, J. Hydrol., 236, 54-77, 2000.

Bates, P. D., Stewart, M. D., Siggers, G. B., Smith, C. N., Hervouet, J. M., and Sellin, R. H. J.: Internal and external validation of a two-dimensional finite element model for river flood simulation, Proceedings of the Institution of Civil Engineers, Water Mar. Energy, 130, 127-141, 1998.

Bates, P. D., Horritt, M. S., and Fewtrell, T. J.: A simple inertial formulation of the shallow water equations for efficient two dimensional flood inundation modelling, J. Hydrol., 387, 33-45, 2010.

Begnudelli, L. and Sanders, B. F.: Simulation of the St. Francis dam-break flood, J. Eng. Mech., 133, 1200-1212, 2007.

Brown, J. D., Spencer, T., and Moeller, I.: Modelling storm surge flooding of an urban area with particular reference to modelling uncertainties: a case study of Canvey Island, United Kingdom, Water Resour. Res., 43, W06402, doi:10.1029/2005WR004597, 2007.

Chow, V.: Open Channel Hydraulics, McGraw-Hill, New York, 1959.

Cunge, J. A., Holly, F. M., and Verwey, A.: Practical Aspects of Computational River Hydraulics, Pitman, London, UK, 420 pp., 1980.

de Almeida, G. A. M. and Bates, P.: Applicability of the local inertial approximation of the shallow water equations to flood modeling, Water Resour. Res., 49, 4833-4844, doi:10.1002/wrcr.20366, 2013. 
de Almeida, G. A. M., Bates, P. D., Freer, J. E., and Souvignet, M.: Improving the stability of a simple formulation of the shallow water equations for 2-D flood modelling, Water Resour. Res., 48, W05528, doi:10.1029/2011WR011570, 2012.

DEFRA: Interim code of practice for Sustainable Drainage Systems, National SUDS Working Group, UK, 2004.

DEFRA: Future Water: The Government's Water Strategy for England, CM7319, London, 2008.

Djokic, D. and Maidment, D. R.: Terrain analysis for urban stormwater modelling, Hydrol. Process., 5, 115-124, 1991.

EA - Environmental Agency: http://www.environment-agency. gov.uk/homeandleisure/floods/142209.aspx (last access: October 2013), 2011.

Fewtrell, T. J., Bates, P. D., Horritt, M., and Hunter, N. M.: Evaluating the effect of scale in flood inundation modelling in urban environments, Hydrol. Process., 22, 5107-5118, 2008.

Fewtrell, T. J., Duncan, A., Sampson, C. C., Neal, J. C., and Bates, P. D.: Benchmarking urban flood models of varying complexity and scale using high resolution terrestrial LiDAR data, Phys. Chem. Earth, 36, 281-291, 2011.

Gallegos, H. A., Schubert, J. E., and Sanders, B. F.: Twodimensional, high-resolution modeling of urban dam-break flooding: A case study of Baldwin Hills California, Adv. Water Resour., 32, 1323-1335, 2009.

Gee, D. M., Anderson, M. G., and Baird, L.: Large scale floodplain modelling, Earth Surf. Proc. Land., 15, 512-523, 1990.

Guinot, V. and Soares-Frazao, S.: Flux and source term discretization in two-dimensional shallow water models with porosity on unstructured grids, Int. J. Num. Meth. Fluid., 50, 309-345, 2006.

Horritt, M. S.: Calibration of a two-dimensional finite element flood flow model using satellite radar imagery, Water Resour. Res., 36, 3279-3291, 2000.

Horritt, M. S. and Bates, P. D.: Effect of spatial resolution on a raster based model of flood flow, J. Hydrol., 253, 239-249, 2001.

Horritt, M. S. and Bates, P. D.: Evaluation of 1-D and 2-D numerical models for predicting river flood inundation, J. Hydrol., 268, 8799, 2002.

Hsu, M. H., Chen, S. H., and Chang, T. J.: Inundation simulation for urban drainage basin with storm sewer system, J. Hydrol., 234, 21-37, 2000 .

Hunter, N. M., Horritt, M. S., Bates, P. D., Wilson, M. D., and Werner, M. G. F.: An adaptive time step solution for raster-based storage cell modelling of floodplain inundation, Adv. Water Resour., 28, 975-991, 2005.

Hunter, N. M., Bates, P. D., Néelz, S., Pender, G., Villanueva, I., Wright, N. G., Liang, D., Falconer, R. A., Lin, B., Waller, S., Crossley, A. J., and Mason, D. C.: Benchmarking 2D hydraulic models for urban flooding, Proc. Inst. Civil Eng. - Water Manage., 161, 13-30, 2008.

Institute of Hydrology: Flood Estimation Handbook, Institute of Hydrology, Wallingford, 1999.

Jonkman, S. N. and Kelman, I.: An analyses of the causes and circumstances of flood disaster deaths, Disasters, 29, 75-97, 2005.

Kelman, I. and Spence, R.: An overview of flood actions on buildings, Eng. Geol., 73, 297-309, 2004.

Kok, M., Huizinga, H. J., Vrouwenfelder, A. C. W. M., and Barendregt, A.: Standard Method 2004, Damage and Casualties caused by Flooding, Highway and Hydraulic Engineering Department, the Netherlands, 2005.
LeVeque, R. J.: Finite Volume Methods for Hyperbolic Problems, Cambridge Univ. Press., Cambridge, Mass., 257 pp., 2002.

Lichti, D., Pfeifer, N., and Maas, H.: ISPRS Journal of Photogrammetry and Remote Sensing theme issue "Terrestrial Laser Scanning”, ISPRS J. Photogramm. Remote Sens., 63, 1-3, 2008.

Mason, D. C., Cobby, D. M., Horritt, M. S., and Bates, P. D.: Floodplain friction parameterization in two-dimensional river flood models using vegetation heights derived from airborne scanning laser altimetry, Hydrol. Process., 17, 1711-1732, 2003.

Mason, D. C., Horritt, M. S., Hunter, N. M., and Bates, P. D.: Use of fused airborne scanning laser altimetry and digital map data for urban flood modelling, Hydrol. Process., 21, 1436-1447, 2007.

Merz, B., Hall, J., Disse, M., and Schumann, A.: Fluvial flood risk management in a changing world, Nat. Hazards Earth Syst. Sci., 10, 509-527, doi:10.5194/nhess-10-509-2010, 2010.

Mignot, E., Paquier, A., and Haider, S.: Modeling floods in a dense urban area using 2D shallow water equations, J. Hydrol., 327, 186-199, 2006.

Neal, J. C., Bates, P. D., Fewtrell, T. J., Hunter, N. M., Wilson, M D., and Horritt, M. S.: Distributed whole city water level measurement from the Carlisle 2005 urban flood event and comparison with hydraulic model simulations, J. Hydrol., 368, 42-55, 2009.

Neal, J. C., Villanueva, I., Wright, N., Willis, T., Fewtrell, T., and Bates, P. D.: How much physical complexity is needed to model flood inundation?, Hydrol. Process., 26, 2264-2282, doi:10.1002/hyp.8339, 2011.

Néelz, S. and Pender, G.: Benchmarking of 2D Hydraulic Modelling Packages, SC080035/R2 Environment Agency, Bristol, 2010.

Néelz, S., Pender, G., Villanueva, I., Wilson, M., Wright, N. G., Bates, P., Mason, D., and Whitlow, C.: Using remotely sensed data to support flood modelling, Proceedings of the Institution of Civil Engineers, Water Manage., 159, 35-43, 2006.

Nicholas, A. P. and Mitchell, C. A.: Numerical simulation of overbank processes in topographically complex floodplain environments, Hydrol. Process., 17, 727-746, 2003.

Pappenberger, F., Cloke, H. L., Balsamo, G., Ngo-Duc, T., and Oki, T.: Global runoff routing with the hydrological component of the ECMWF NWP system, Int. J. Climatol., 30, 2155-2174, 2009.

Pitt, M.: Learning Lessons from the 2007 Floods, The Pitt Review Cabinet Office London, London, 2008.

Ponce, V. M.: Generalized diffusion wave equation with inertial effects, Water Resour. Res., 26, 1099-1101, 1990.

Roe, P. L.: Approximate riemann solvers, parameter vectors and difference schemes, J. Comput. Phys., 43, 357-372, 1981.

Sampson, C. C., Fewtrell, T. J., Duncan, A., Shaad, K., Horritt, M S., and Bates, P. D.: Use of terrestrial laser scanning data to drive decimetric resolution urban inundation models, Adv. Water Resour., 41, 1-17, 2012.

Schubert, J. E., Sanders, B. F., Smith, M. J., and Wright, N. G.: Unstructured mesh generation and landcover-based resistance for hydrodynamic modeling of urban flooding, Adv. Water Resour., 31, 1603-1621, 2008.

Toro, E. F.: Riemann Solvers and Numerical Methods for Fluid Dynamics, Springer-Verlag, 1999.

Toro, E. F.: Shock-capturing methods for free-surface shallow flows, John Wiley \& Sons Ltd., 2001. 
Tsubaki, R. and Fujita, I.: Unstructured grid generation using LiDAR data for urban flood inundation modelling, Hydrol. Process., 24, 1404-1420, 2010.

Villauneva, I. and Wright, N. G.: Linking Riemann and storage cell models for flood prediction, Water Manage., 159, 27-33, 2005.

Wallingford, H. R.: Flood Risk to People Phase 2, FD2321/TR2 Guidance Document, Defra/Environmental Agency, UK, 2006.

Werner, M. G. F., Hunter, N. M., and Bates, P. D.: Identifiability of distributed floodplain roughness values in flood extent estimation, J. Hydrol., 314, 139-157, 2005.

Wheater, H. S.: Progress in and prospects for fluvial flood modelling, Philos. T. Roy. Soc. A, 360, 1409-1431, 2002.

Wilson, M. D. and Atkinson, P. M.: The use of remotely sensed land cover to derive floodplain friction coefficients for flood inundation modelling, Hydrol. Process., 21, 3576-3586, 2007.
Xia, J., Teo, F. Y., Lin, B., and Falconer, R. A.: Formulation of incipient velocity for flooded vehicles, Nat. Hazards, 58, 1-14, 2010.

Xia, J., Falconer, R. A., Lin, B., and Tan, G.: Modelling flash flood risk in urban areas, Water Manage., 164, 267-282, 2011.

Xia, R.: Impact of coefficients in momentum equation on selection of inertial models, J. Hydraul. Res., 32, 615-621, 1994.

Yu, D. and Lane, S. N.: Urban fluvial flood modelling using a twodimensional diffusion-wave treatment, part 1: mesh resolution effects, Hydrol. Process., 20, 1541-1565, 2006a.

$\mathrm{Yu}$, D. and Lane, S. N.: Urban fluvial flood modelling using a two-dimensional diffusion-wave treatment, part 2: development of a sub-grid-scale treatment, Hydrol. Process., 20, 1567-1583, 2006b. 